\title{
Impact of Maternal Body Mass Index on Progress and Outcome of Labor in Nulliparous Females
}

\author{
Omar Fawzy Kamal El-Sayed ${ }^{1, *}$ M.B.B.CH, Ismail Mohammed Talaat El-Garhy ${ }^{1}$ MD, \\ Ahmed Mohammed Saeed ${ }^{1}$ MD
}

\section{*Corresponding Author: \\ Omar Fawzy Kamal El-Sayed \\ omar.fawzy.kamal@gmail.com}

Received for publication August 17, 2021; Accepted October 16, 2021, Published online October 16, 2021.

CopyrightThe Authors published by Al-Azhar University, Faculty of Medicine, Cairo, Egypt. Users have the right to read, download, copy, distribute, print, search, or link to the full texts of articles under the following conditions: Creative Commons Attribution-Share Alike 4.0 International Public License (CC $B Y-S A$ 4.0).

doi: $10.21608 /$ aimj.2021.91324.1552

${ }^{I}$ Obstetrics and Gynecology Department, Faculty of Medicine, Al-Azhar University Cairo, Egypt.

\begin{abstract}
Background: the body mass index (BMI) is frequently used to classify the severity of obesity and to inform weight-gain guidelines throughout pregnancy.

Aim of the work: to evaluate the impact of BMI of nulliparous females on progress of labour, incidence of peri-partum complications (1ry outcome) and neonatal outcome of these women (secondary outcome).

Patients and methods: This is a prospective cohort study, was carried out on 330nulliparous patients attending the labor ward of Al-Hussein and Sayed Galal hospitals, Al-Azhar University, Egypt, during active phase of labor, divided into 4 groups, from January 2021 until the end of the specified cases.

Results: In terms of weight and BMI, there is a considerable disparity between the 4 groups.

Conclusion: Labor development and labor time varied by BMI category, as evaluated by cervical dilatation rates. As per recent research, a higher BMI in nulliparous women is linked to a higher chance of caesarean birth during labor. This training should be available to first-time mothers prior to conception, and labor ward staff should be informed of this group of women before labour, with a concentration on the issues of analgesia and anesthesia in obese parturients.
\end{abstract}

Keywords: Body mass index; Labor progress; prolonged labor, nulliparous women, obesity.

Disclosure: The authors have no financial interest to declare in relation to the content of this article. The Article Processing Charge was paid for by the authors. Authorship: All authors have a substantial contribution to the article.

\section{INTRODUCTION}

The worldwide prevalence of obesity has increased substantially over the past few decades. Economic, technologic, and lifestyle changes have created an abundance of cheap, high-calorie food coupled with decreased required physical activity. We are eating more and moving less. Obesity is a significant public health concern and is likely to remain so for the foreseeable future ${ }^{1}$.

The most commonly used measurement for defining obesity is BMI, which refers to an individual's weight in kilograms divided by the square of his or her height in meters. Individuals are deemed overweight when they have a BMI between 25 and $30 \mathrm{~kg} / \mathrm{m} 2$; obesity is defined as a BMI greater than or equal to $30 \mathrm{~kg} / \mathrm{m} 2$, and morbid obesity is defined as a BMI greater or equal to $40 \mathrm{~kg} / \mathrm{m} 2$. It is important to note, however, that BMI can be misleading ${ }^{2}$.

Both increased and decreased BMI have been demonstrated to be associated with an increased rate of adverse events ${ }^{3}$.

Some studies have investigated the impact of maternal BMI on the progress of labor and the length of labor; patients with increased BMI have been 
[vertex] presentation and Occipito-Anterior position and in active phase of labour [dilatation of at least 4 $\mathrm{cm}]$

Exclusion criteria are: Multiparous women, age below 20 or over 40, multifetal Pregnancy, major fetal anomalies, malposition, premature Rupture of membranes, maternal pregestational and gestational medical disorders other than obesity and labor induction (by stripping, amniotomy, prostaglandins or oxytocin infusion)

Methods

The following will be done to the participants:

The pregnant women who took part in the study voluntarily gave their written consent

Name, age, occupation, and location are all taken as part of the whole history

Medical or surgical history (particularly bariatric procedures), any drug sensitivity, or obstetric or operative problem.

Thorough Clinical Examination: General assessment: vital signs (blood pressure and pulse, respiratory rate and temperature), length (in $\mathrm{cm}$ ) and weight (in $\mathrm{kg}$ ) metrics (Body mass will be evaluated with a calibrated scale) while topics are wearing the lightest clothing possible and BMI will be determined), head and neck evaluation for jaundice, pallor, pigmentations, edoema, goitre, enlarged lymph nodes, and congested necrosis Inspection: to determine the size of the abdomen, the presence of striae gravidarum, and the presence of pigmentations such as linea nigra. Fundal level, fundal grip to identify the part of the fetus occupying the fundus, umbilical grip to detect the back and foetal limbs, and first pelvic grip to identify the part of the foetus occupying the lower uterine segment and to detect engagement are all examples of obstetric palpation (Maneuvers of Leopold).

Laboratory Investigations: $\mathrm{CBC}$, kidney and liver function, coagulation profile and FBS, PPBS, HBA1C and urine analysis

Ultrasound: Ultrasound examination will be done, to Asses Biophysical Profile (BPP), which includes: Amniotic Fluid Index (AFI), Fetal Movement, Fetal Tone, and Fetal Breathing, number of fetuses
(Exclusion of multiple pregnancies), position of the Placenta, biometry, Gestational age, Presentation (at term), estimated Fetal weight using Hadlock formula depending on BPD, AC, FL for assessment of normal growth, macrosomia, and IUGR and umbilical artery Doppler flowmetry for assessment of fetal condition.

Monitoring progress and complications (Primary outcome): Patients had been weighed and had their height measured. This study depends on the pre-labor weight rather than pre- pregnancy weight. Patients had been divided into groups using their BMI based on WHO criteria. Group A had been include women with normal BMI of [18.5- 24.9]. Group B had been include overweight women with BMI of [25- 29.9]. Group C had been include obese women with BMI of at least 30 which will be subdivided into 3 subgroups corresponding to the 3 classes of obesity according to who criteria [10], Sub- group C1 with BMI of 30-34.9, Sub-group C2 with BMI of 35-39.9, Sub-group C3 with BMI of at least 40 . Group D had been include underweight women with body mass index less than 18.5. Friedman curve had been used to monitor progress of labor in terms of cervical dilatation and head descent vs. time.

Monitoring for complication: A check-list of peripartum complications had been prepared and fulfilled for each patient of each group

Neonatal assessment (secondary outcome): The neonatal birth weight. Follow up the neonate for Apgar score at $1 \&$ at $5 \mathrm{~min}$ by trained pediatrician. Neonatal admission to ICU

Data collection and statistical analysis: Utilizing Microsoft Excel software, data from the history, basic medical examination, laboratory investigations, and outcome measures are coded, input, and analyzed. Statistical Package for the Social Sciences (SPSS version 20.0) (Statistical Package for the Social Sciences) software was used to analyses the data. Per the type of data, qualitative data is represented as a number and a percentage, while quantitative data is represented as a mean and standard deviation. the next tests were used to determine the significance of differences: correlation by Pearson's correlation or Spearman's correlation. For significant results, the $\mathrm{P}$ value was set at 0.05 , and for very significant outcomes, it was set at $<0.001$.

RESULTS

In terms of weight and BMI, there is a considerable disparity between the 4 groups. Table (1)

\begin{tabular}{|c|c|c|c|c|c|c|}
\hline & $\begin{array}{l}\text { Group A } \\
(n=55)\end{array}$ & $\begin{array}{l}\text { Group B } \\
(n=55)\end{array}$ & $\begin{array}{l}\text { Group C } \\
(n=165)\end{array}$ & $\begin{array}{l}\text { Group D } \\
(n=55)\end{array}$ & $\mathbf{F}$ & $\mathbf{P}$ \\
\hline $\begin{array}{l}\text { Age (years) } \\
\text { Mean } \pm \text { SD }\end{array}$ & $27.43 \pm 3.12$ & $26.04 \pm 3.83$ & $28.07 \pm 5.53$ & $27.71 \pm 4.07$ & 2.59 & .053 \\
\hline $\begin{array}{l}\text { Weight (kg) } \\
\text { Mean } \pm \text { SD }\end{array}$ & $71.38 \pm 6.51$ & $81.55 \pm 8.64$ & $94.43 \pm 7.91$ & $54.76 \pm 2.59$ & 465 & .000 \\
\hline $\begin{array}{l}\text { Height }(\mathrm{cm}) \\
\text { Mean } \pm \text { SD }\end{array}$ & $1.71 \pm 0.062$ & $1.69 \pm 0.051$ & $1.7 \pm 0.078$ & $1.72 \pm 0.068$ & 1.99 & .114 \\
\hline $\begin{array}{l}\text { BMI }\left(\mathrm{kg} / \mathrm{m}^{2}\right) \\
\text { Mean } \pm \mathrm{SD}\end{array}$ & $22.36 \pm 1.32$ & $29.88 \pm 3.42$ & $36.82 \pm 4.69$ & $17.12 \pm 1.46$ & 531 & .000 \\
\hline
\end{tabular}

Table 1: Demographic data between the studied groups 
There is a substantial variations in birth weight and Apgar at 1 and 5 minutes across the four groups tested. Table (2)

\begin{tabular}{|c|c|c|c|c|c|c|}
\hline & $\begin{array}{l}\text { Group A } \\
(n=55)\end{array}$ & $\begin{array}{l}\text { Group B } \\
(n=55)\end{array}$ & $\begin{array}{l}\text { Group C } \\
(n=165)\end{array}$ & $\begin{array}{l}\text { Group D } \\
(n=55)\end{array}$ & $\mathbf{F}$ & $\mathbf{P}$ \\
\hline $\begin{array}{l}\text { GA (weeks) } \\
\text { Mean } \pm \text { SD }\end{array}$ & $37.56 \pm 2.31$ & $37.7 \pm 2.91$ & $36.65 \pm 3.12$ & $37.1 \pm 2.82$ & 2.51 & .059 \\
\hline $\begin{array}{l}\text { Birth weight (kg) } \\
\text { Mean } \pm \text { SD }\end{array}$ & $3.33 \pm 0.98$ & $2.59 \pm 1.06$ & $2.67 \pm 1.21$ & $2.16 \pm 1.71$ & 8.21 & .000 \\
\hline $\begin{array}{l}\text { Apgar at } 1 \text { min } \\
\text { Mean } \pm \text { SD }\end{array}$ & $7.1 \pm .874$ & $6.84 \pm 1.12$ & $6.51 \pm 1.57$ & $7.02 \pm 1.07$ & 3.91 & .009 \\
\hline $\begin{array}{l}\text { Apgar at } 5 \text { min } \\
\text { Mean } \pm \text { SD }\end{array}$ & $9.26 \pm 1.44$ & $8.46 \pm 2.55$ & $8.23 \pm 2.43$ & $8.81 \pm 1.56$ & 3.39 & .018 \\
\hline
\end{tabular}

Table 2: Neonatal characteristics of the studied groups

There is a significant difference between the four studied groups regarding active phase duration, cervical dilation rate, second stage duration and labor duration. Table (3)

\begin{tabular}{|c|c|c|c|c|c|c|}
\hline & $\begin{array}{l}\text { Group A } \\
(\mathbf{n}=55)\end{array}$ & $\begin{array}{l}\text { Group B } \\
(\mathbf{n}=55)\end{array}$ & $\begin{array}{l}\begin{array}{l}\text { Group C } \\
(n=165)\end{array} \\
\end{array}$ & $\begin{array}{l}\text { Group D } \\
(\mathbf{n}=55)\end{array}$ & $\mathbf{F}$ & $\mathbf{P}$ \\
\hline $\begin{array}{l}\text { Cervical dilatation at admission }(\mathrm{cm}) \\
\text { Mean } \pm \text { SD }\end{array}$ & $4.12 \pm 0.375$ & $4.13 \pm 0.356$ & $4.13 \pm 0.318$ & $4.16 \pm 0.359$ & .147 & .932 \\
\hline $\begin{array}{l}\text { Active phase duration (h) } \\
\text { Mean } \pm \text { SD }\end{array}$ & $5.58 \pm 1.65$ & $6.24 \pm 1.83$ & $6.95 \pm 2.06$ & $4.13 \pm 0.131$ & 37 & .000 \\
\hline $\begin{array}{l}\text { Cervical dilation rate }(\mathrm{cm} / \mathrm{h}) \\
\text { Mean } \pm \text { SD }\end{array}$ & $1.31 \pm 0.576$ & $1.15 \pm 0.312$ & $1.07 \pm 0.354$ & $1.49 \pm 0.412$ & 16.8 & .000 \\
\hline $\begin{array}{l}\text { Second stage duration }(h) \\
\text { Mean } \pm \text { SD }\end{array}$ & $1.79 \pm 0.425$ & $1.95 \pm 0.762$ & $2.21 \pm 0.832$ & $1.68 \pm 0.315$ & 10.5 & .000 \\
\hline $\begin{array}{l}\text { Labor duration (h) } \\
\text { Mean } \pm \text { SD }\end{array}$ & $7.15 \pm 1.65$ & $8.02 \pm 1.79$ & $8.54 \pm 2.1$ & $5.78 \pm 0.955$ & 33.8 & .000 \\
\hline
\end{tabular}

Table 3: Intrapartum data of the studied groups

There is a significant difference between the four studied groups regarding protracted dilatation and type of delivery. Table (4)

\begin{tabular}{|c|c|c|c|c|c|c|}
\hline & $\begin{array}{l}\text { Group A } \\
(n=55)\end{array}$ & $\begin{array}{l}\text { Group B } \\
(n=55)\end{array}$ & $\begin{array}{l}\begin{array}{l}\text { Group C } \\
(n=165)\end{array} \\
\end{array}$ & $\begin{array}{l}\begin{array}{l}\text { Group D } \\
(n=55)\end{array} \\
\end{array}$ & $\square^{2}$ & $\mathbf{P}$ \\
\hline \multicolumn{7}{|l|}{ Labor anomalies } \\
\hline Protracted dilatation & $9(16.4 \%)$ & $14(25.5 \%)$ & $52(31.5 \%)$ & $6(10.9 \%)$ & 11.9 & .008 \\
\hline Protracted descent & $3(5.5 \%)$ & $4(7.3 \%)$ & $13(7.9 \%)$ & $3(5.5 \%)$ & .608 & .895 \\
\hline Arrest of dilatation & $2(3.6 \%)$ & $3(5.5 \%)$ & $10(6.1 \%)$ & $2(3.6 \%)$ & .806 & .848 \\
\hline Arrest of descent & $1(1.8 \%)$ & $2(3.6 \%)$ & $7(4.2 \%)$ & $1(1.8 \%)$ & 1.22 & .748 \\
\hline \multicolumn{7}{|l|}{ Delivery } \\
\hline Vaginal delivery & $31(56.4 \%)$ & $25(45.5 \%)$ & $68(41.2 \%)$ & $37(67.3 \%)$ & \multirow[t]{2}{*}{12.8} & \multirow[t]{2}{*}{.005} \\
\hline Cesarean delivery & $24(43.6 \%)$ & $30(54.5 \%)$ & $97(58.8 \%)$ & $18(32.7 \%)$ & & \\
\hline
\end{tabular}

Table 4: Labor and delivery outcome of the studied groups

There is a substantial variations between the four studied groups regarding episiotomy and postpartum hemorrhage. Table (5)

\begin{tabular}{|c|c|c|c|c|c|c|}
\hline & $\begin{array}{l}\text { Group A } \\
(\mathbf{n}=55)\end{array}$ & $\begin{array}{l}\text { Group B } \\
(n=55)\end{array}$ & $\begin{array}{l}\text { Group C } \\
(n=165)\end{array}$ & $\begin{array}{l}\text { Group D } \\
(\mathbf{n}=55)\end{array}$ & $\square^{2}$ & $\mathbf{P}$ \\
\hline \multicolumn{7}{|l|}{ Maternal complication } \\
\hline Perineal tear & $2(3.6 \%)$ & $3(5.5 \%)$ & $16(9.7 \%)$ & $1(1.8 \%)$ & 5.46 & .141 \\
\hline Vaginal tear & $6(10.9 \%)$ & $7(12.7 \%)$ & $29(17.6 \%)$ & $5(9.1 \%)$ & 3.3 & .348 \\
\hline Episiotomy* & $19(61.3 \%)$ & $16(64 \%)$ & $54(79.4 \%)$ & $18(48.7 \%)$ & 10.8 & .013 \\
\hline Postpartum hemorrhage & $1(1.8 \%)$ & $2(3.6 \%)$ & $18(10.9 \%)$ & $2(3.6 \%)$ & 8.09 & .044 \\
\hline $\begin{array}{l}\text { Pregnancy } \\
\text { Hypertension }\end{array}$ & 0 & $3(5.5 \%)$ & $14(8.5 \%)$ & $2(3.6 \%)$ & 6.09 & .107 \\
\hline \multicolumn{7}{|l|}{ Neonatal complications } \\
\hline Shoulder dystocia & $1(1.8 \%)$ & $1(1.8 \%)$ & $9(5.5 \%)$ & 0 & 4.98 & .173 \\
\hline Fetal distress & $5(9.1 \%)$ & $6(10.9 \%)$ & $25(15.2 \%)$ & $4(7.3 \%)$ & 3.19 & .364 \\
\hline Cervical dystocia & 0 & $1(1.8 \%)$ & $3(1.8 \%)$ & 0 & 2.03 & .567 \\
\hline Stillbirth & $2(3.6 \%)$ & $3(5.5 \%)$ & $13(7.9 \%)$ & $1(1.8 \%)$ & 3.41 & .333 \\
\hline NICU admission & $7(12.7 \%)$ & $8(14.5 \%)$ & $33(20 \%)$ & $5(9.1 \%)$ & 4.43 & .219 \\
\hline
\end{tabular}

* Percentage calculated among all vaginal deliveries only.

Table 5: Complications distribution of the studied groups

There is no discernible difference between the subgroups tested.. Table (6) 


\begin{tabular}{|c|c|c|c|c|c|}
\hline & $\begin{array}{l}\text { Group C1 } \\
(\mathrm{n}=55)\end{array}$ & $\begin{array}{l}\text { Group C2 } \\
(n=55)\end{array}$ & $\begin{array}{l}\text { Group C3 } \\
(\mathrm{n}=55)\end{array}$ & $\mathbf{F}$ & $\mathbf{P}$ \\
\hline $\begin{array}{l}\text { Cervical dilatation at admission }(\mathrm{cm}) \\
\text { Mean } \pm \text { SD }\end{array}$ & $4.12 \pm 0.442$ & $4.13 \pm 0.339$ & $4.13 \pm 0.372$ & .012 & .988 \\
\hline $\begin{array}{l}\text { Active phase duration }(h) \\
\text { Mean } \pm \text { SD }\end{array}$ & $6.73 \pm 1.57$ & $6.98 \pm 1.49$ & $7.11 \pm 1.96$ & .722 & .487 \\
\hline $\begin{array}{l}\text { Cervical dilation rate }(\mathrm{cm} / \mathrm{h}) \\
\text { Mean } \pm \text { SD }\end{array}$ & $1.12 \pm 0.416$ & $1.04 \pm 0.362$ & $0.968 \pm 0.385$ & 2.11 & .125 \\
\hline $\begin{array}{l}\text { Second stage duration }(\mathrm{h}) \\
\text { Mean } \pm \text { SD }\end{array}$ & $2.07 \pm 0.825$ & $2.15 \pm 0.795$ & $2.31 \pm 0.787$ & 1.28 & .282 \\
\hline $\begin{array}{l}\text { Labor duration }(h) \\
\text { Mean } \pm \text { SD }\end{array}$ & $8.39 \pm 1.86$ & $8.62 \pm 2.09$ & $8.98 \pm 2.13$ & 1.18 & .309 \\
\hline
\end{tabular}

Table 6: Intrapartum data of the studied groups

In terms of problems, there is no substantial difference between the four groups evaluated. Table (7)

\begin{tabular}{|c|c|c|c|c|c|}
\hline & $\begin{array}{l}\text { Group C1 } \\
(n=55)\end{array}$ & $\begin{array}{l}\text { Group C2 } \\
(n=55)\end{array}$ & $\begin{array}{l}\text { Group C3 } \\
(n=55)\end{array}$ & $\square^{2}$ & $\mathbf{P}$ \\
\hline \multicolumn{6}{|l|}{ Maternal complication } \\
\hline Perineal tear & $3(5.5 \%)$ & $6(10.9 \%)$ & $7(12.7 \%)$ & 1.79 & .407 \\
\hline Vaginal tear & $9(16.4 \%)$ & $11(20 \%)$ & $9(16.4 \%)$ & .335 & .846 \\
\hline Episiotomy* & $19(82.6 \%)$ & $19(76 \%)$ & $16(80 \%)$ & .326 & .849 \\
\hline Postpartum hemorrhage & $2(3.6 \%)$ & $6(10.9 \%)$ & $10(18.2 \%)$ & 5.99 & .051 \\
\hline $\begin{array}{l}\text { Pregnancy } \quad \text { induced } \\
\text { Hypertension }\end{array}$ & $3(5.5 \%)$ & $5(9.1 \%)$ & $6(10.9 \%)$ & 1.09 & .579 \\
\hline \multicolumn{6}{|l|}{ Neonatal complications } \\
\hline Shoulder dystocia & $1(1.8 \%)$ & $4(7.3 \%)$ & $5(9.1 \%)$ & 2.77 & .251 \\
\hline Fetal distress & $5(9.1 \%)$ & $9(16.4 \%)$ & $11(20 \%)$ & 2.64 & .267 \\
\hline Cervical dystocia & 0 & $1(1.8 \%)$ & $2(3.6 \%)$ & 2.04 & .361 \\
\hline Stillbirth & $4(7.3 \%)$ & $4(7.3 \%)$ & $5(9.1 \%)$ & .167 & .919 \\
\hline NICU admission & $7(12.7 \%)$ & $12(21.8 \%)$ & $15(27.3 \%)$ & 3.63 & .163 \\
\hline
\end{tabular}

* Percentage calculated among all vaginal deliveries only.

Table 7: Complications distribution of the studied groups

\section{DISCUSSION}

The World Health Organization has designated obesity as a "pandemic nutritional disorder that poses a rapidly growing threat to the health of populations in an increasing number of countries worldwide." 6 .

BMI is the most widely utilized metric for determining obesity. It is determined by dividing an individual's weight in kilogrammes by the square of his or her height in meters. Obesity is referred to as having a BMI larger than or equal to $30 \mathrm{~kg} / \mathrm{m} 2$, whereas morbid obesity is identified as having a BMI greater than or equal to $40 \mathrm{~kg} / \mathrm{m} 2$.

Previous study has focused into the impact of maternal BMI on labor time and development; women with higher BMI have been reported to have delayed labor progress, labor dysfunction, and a greater caesarean delivery rate ${ }^{5}$.

Our study was a prospective cohort study that included nulliparous patients attending the labour wards of Al-Hussein and Sayed Galal hospitals, AlAzhar University, Egypt, from January 2021 until the end of the specified cases.

They divided for four: groups A included women with normal BMI of (18.5 - 25), groups B included women with normal BMI of $(25-29.9)$, groups C included women with normal BMI of (at least 30) Sub- group C1 with BMI of 30-34.9 Sub-group C2 with BMI of 35-39.9, Sub group C3 with BMI of at least 40 and Group D included underweight women with body mass index less than 18.5.

In terms of demographic data in the four groups, our findings revealed that there was a significant difference between the four groups in terms of weight and BMI; however, there was no significant difference in terms of age and height.

In terms of demographic data among group $\mathrm{C}$ subgroups, our findings revealed a significant difference in weight and BMI between the studied subgroups.

Maged et al. ${ }^{5}$ showed no significant variations in mother age, height, or admission time across the research groups, which backed up our findings. However, there were substantial differences in mother and neonatal delivery weights between the groups.

Furthermore, the study of Kominiarek et al., ${ }^{8}$ discovered major variations in maternal age, height, and weight $(\mathrm{kg})$ at labour between the study groups as $p$ - values $>0.0001$. Our study as regards Neonatal characteristics of the studied groups revealed a significant difference between the four studied groups regarding birth weight and Apgar at 1 and 5 minutes.

The findings of Kominiarek et al., ${ }^{8}$ support our findings, as they discovered a significant difference 
in birth weight between the study groups with a $\mathrm{p}$ value greater than 0.0001 .

Martino et al., ${ }^{9}$ found that, whereas calculated fetal weight at 34 weeks gestation was greater when GDM was associated with obesity, size and weight at delivery were not varied between these groups.

Bergholt et al. ${ }^{10}$ discovered that an increase in fetal birth weight increased the risk of caesarean delivery for both suspected fetal distress and failure to develop.

In our study, we discovered that there was an important variations between the four studied groups of active phase duration, cervical dilation rate, second stage duration, and labour duration.

In terms of intrapartum data among group $\mathrm{C}$ subgroups, our findings revealed that there was no great disparity between the subgroups studied.

Maged et al., ${ }^{5}$ discovered that the incidence of cervical dilatation differed between groups, with the obese group having the lowest rate, confirming our findings. Similarly, the active phase of labor and the overall duration of labor varied; both were longer in patients with obese BMI values.

However, they determined that all patients' second stages of labor lasted the same amount of time, and there were no significant variations in pregnancy duration or cervical dilation at admission between the research groups.

Also, in the study of Kominiarek et al., ${ }^{8}$, they observed that the study groups had significant variations in pregnancy time or cervical dilatation upon admission.

In our study, we discovered a significant difference between the four studied groups in terms of protracted dilatation and type of delivery.

In our study, there was no significant difference between the studied subgroups in terms of labour and delivery outcome.

In terms of labor and delivery outcomes, Maged et al., 5 discovered that the incidence of protracted cervical dilatation, but not protracted descend or arrest disorders, differed between the 3 groups, with rising incidence of protracted cervical dilatation registered as patient BMI increased.

They also discovered that the proportion of patients who had caesarean deliveries varied between groups, but there was no large difference in the indications among patients who had caesarean deliveries, with the obese group having the highest caesarean delivery rate.

The study by Kominiarek et al., ${ }^{8}$ found a significant difference between caesarean delivery rate and BMI, with a $\mathrm{p}$ value greater than 0.0001 .

In contrast to our findings, the Vinturache et al., ${ }^{11}$ cohort study included 65.8 percent normal weight, 23.6 percent overweight, and 10.6 percent obese women. They discovered that BMI prior to pregnancy was not a significant risk factor for mode of delivery.
In terms of maternal and fetal complications, our study found a significant difference between the four groups studied in terms of episiotomy and postpartum hemorrhage.

There was no significant difference between the studied subgroups in terms of maternal and fetal complication in our study.

When it came to mother and fetal problems, Maged et al., ${ }^{5}$ found no changes in the occurrence of shoulder dystocia, fetal distress, vaginal or perineal tears, or doses of pethidine or oxytocin across the groups.

The obese group had the highest rate of post-cesarean delivery hypotension; no other variations in postcesarean delivery side effects were discovered. Obese patients were the most likely to have an episiotomy.

\section{CONCLUSION}

Finally, there were differences in labor progression (as evaluated by cervical dilatation frequencies and labor length) across BMI classes. Partograms with separate action lines for different BMI groups should be used in future study. Labor-management strategies must be adapted depending on patient BMI to give all women an equal likelihood of vaginal birth. By simply adding more duration and clarifying labor dysfunction anomalies, obstetricians' decisions about caesarean deliveries could be influenced, and caesarean delivery rates could be reduced.

\section{REFERENCES}

1. Agha M, Agha R. The rising prevalence of obesity: part A: impact on public health. International journal of surgery. Oncology. 2017; 2(7):e17.

2. Purnell JQ. Definitions, classification, and epidemiology of obesity. InEndotext [Internet] 2018 Apr 12. MD Text. 2018; 218-33.

3. Denison, F. C., Norwood, P., Bhattacharya, S., Duffy, A., Mahmood, T., Morris, C., et al. Association between maternal body mass index during pregnancy, short- term morbidity, and increased health service costs: a population- based study. BJOG: An International Journal of Obstetrics \& Gynaecology. 2014; 121(1), 72-82.

4. Ellis JA, Brown CM, Barger B, Carlson NS. Influence of maternal obesity on labor induction: a systematic review and meta- analysis. Journal of midwifery \& women's health. 2019; 64(1):55-67.

5. Maged AM, Belal DS, Marie HM, Rashwan H, Abdelaziz S, Gabr AA, et al. Prospective study of the effect of maternal body mass index on labor progress in nulliparous women in Egypt. International Journal of Gynecology \& Obstetrics. 2017; 139(3):329-35.

6. Popkin, B. M., Adair, L. S., \& Ng, S. W. Global nutrition transition and the pandemic of obesity in developing countries. Nutrition reviews. 2012; 70(1), 3-21. 
7. Weir, C. B., \& Jan, A. . BMI .2019; classification percentile and cut off points.

8. Kominiarek, M. A., Zhang, J., VanVeldhuisen, P., Troendle, J., Beaver, J., \& Hibbard, J. U. Contemporary labor patterns: the impact of maternal body mass index. American journal of obstetrics and gynecology. 2011; 205(3), 244-e1.

9. Martino, J., Sebert, S., Segura, M. T., Garcia-Valdes, L., Florido, J., Padilla, M. C., et al. Maternal body weight and gestational diabetes differentially influence placental and pregnancy outcomes. The Journal of Clinical Endocrinology \& Metabolism. 2016; 101(1), 59-68.
10. Bergholt T, Lim LK, Jorgensen JS, Robson MS. Maternal

body mass index in the first trimester and risk of cesarean delivery in nulliparous women in spontaneous labor. Am. $J$. Obstet. Gynecol. 2007; 196:163.e1-163e5.

11. Vinturache, A., Moledina, N., McDonald, S., Slater, D., \& Tough, S. Pre-pregnancy Body Mass Index (BMI) and delivery outcomes in a Canadian population. BMC pregnancy and childbirth. 2014; 14(1), 1-10. 